DOI: $10.1515 /$ rpp-2016-0001

Doctor of Pedagogical Sciences, Full Professor, NATALIYA MUKAN

Lviv Polytechnic National University, Ukraine Address: 12 Stepan Bandera St., Lviv, 79013, Ukraine

E-mail: nmukan@polynet.lviv.ua

$\mathrm{PhD}$ in Pedagogical Sciences, Associate Professor, IRYNA MYSKIV

Lviv Polytechnic National University, Ukraine

Address: 12 Stepan Bandera St., Lviv, 79013, Ukraine

E-mail: myskiviryna@i.ua

Senior Instructor, SVITLANA KRAVETS

Lviv Polytechnic National University, Ukraine

Address: 12 Stepan Bandera St., Lviv, 79013, Ukraine E-mail: s.f.kravets@gmail.com

\title{
THE MODEL OF UNIFICATION AND THE MODEL OF DIVERSIFICATION OF PUBLIC SCHOOL TEACHERS' CONTINUING PROFESSIONAL DEVELOPMENT IN GREAT BRITAIN, CANADA AND THE USA
}

\begin{abstract}
In the article the theoretical framework of public school teachers' continuing professional development (CPD) in Great Britain, Canada and the USA has been presented. The main objectives have been defined as theoretical analysis of scientific and pedagogical literature, which highlights different aspects of the problem under research; presentation and characteristic of two models: the model of unification and the model of diversification of teachers' professional development in the systems of continuing pedagogical education of Great Britain, Canada and the USA by the dominant traits. Their major components have been defined and specified. Public school teachers' CPD has been studied by foreign and domestic scientists: content of public school teachers' CPD (N. Dana Fichtman, M. Rees, A. Ross, S. Zepeda); CPD programs (C. Pratt); public school teachers' CPD models, methods and forms (K. Duinlan, P. Grimmet, G. Troia, P. Wong); continuous professional education (Ya. Belmaz, A. Kuzminskyy, O. Kuznyetsova). The research methodology comprises theoretical (logical, induction and deduction, comparison and compatibility, structural and systematic, analysis and synthesis) and applied (observations, questioning and interviewing) methods. The research results have been presented.

Key words: theoretical framework, the model of unification, the model of diversification, public school teachers, CPD, Great Britain, Canada, the USA.
\end{abstract}

\section{INTRODUCTION}

Nowadays particular attention and importance are given to public school teachers' continuing professional development. The major task of the public school is to prepare students for being ready to face challenges of economic, social, multicultural character arising in everyday life. Continuing professional development is one of the most significant factors promoting the improvement of students' achievements. The necessity of teachers' continuing professional development, for them to be able to provide high-quality educational services and to improve the work of public schools, is emphasized.

The study and analysis of the experience of teachers' professional development organization in Great Britain, Canada, the USA are an important source of information, 
necessary for determining strategic directions of developing systems of continuing pedagogical education in Ukraine in the scopes of which teachers' professional development is realized. Great Britain, Canada and the USA are the countries that play a leading role in the international educational environment. These countries are making substantial investments in the development of their educational systems, understanding that this will guarantee social stability and the increase of the well-being of their citizens and their countries. One of the proofs of the high-quality educational services provided by the teachers in the systems of school education in the countries being studied is active participation of their students in various international contests, subject competitions, programs as well as their ability to enter the world's most prestigious higher educational institutions after leaving public schools. The countries' governments provide incentives to improve the quality of pedagogical activities through adopting national programs, developing special projects, working out standards of the teaching profession and teachers' professional development, increasing financing for their training as well as intensifying scientific research in the sphere of teachers' professional development etc.

\section{THE AIM OF THE STUDY}

The presentation of two models of public school teachers' CPD in Great Britain, Canada and the USA is the research aim. The authors have defined the following objectives: 1) to conduct the analysis of scientific-pedagogical literature, which highlights different aspects of the problem under research, and 2) to present the model of unification of teachers' professional development and the model of diversification of teachers' professional development in the systems of continuing pedagogical education of Great Britain, Canada and the USA by the dominant traits.

\section{THEORETICAL FRAMEWORK AND RESEARCH METHODS}

It has been found that research of teachers' professional development is done using acmeological (Field, 2001, Joyce, 2010), axiological (Clarke, 1995, Kelley, 2010), andragogical (Beaty, 1998), intercultural (Gay \& Howard, 2000), competence (Cochran-Smith, 2003; Kauchak, 2010), constructivist (Andrew, 2010; Baker, 1999; Reeves, 2010), systemic (Pratt, 2000; Villegas-Reimers, 2003), structural and functional (Lieberman \& Darling-Hammond, 2010; Scribner, 1999) approaches etc. Implicit development of the system of continuing pedagogical education is determined by the process of active implementation of scientific research results that forms the fundamentals for creating technological and academic as well as practical and phenomenological models of teachers' professional development.

A complex of theoretical methods has been used as the basis of the research: logical method used to discover objective regularities for creating a set of concepts and judgments in the field of public school teachers' CPD; induction and deduction used for gathering theoretical and factual material, its generalization as well as realization and interpretation of separate phenomena of pedagogical reality; the method of comparison and compatibility that allowed to define similarities and differences in the process of teachers' professional development in the countries being studied; the structural and systematic method used for considering structural elements and functional peculiarities of the systems of continuing pedagogical education of Great Britain, Canada and the USA; analysis and synthesis used for specifying content, models, methods and forms of teachers' CPD, for forming theories and hypotheses explaining specifics of its implementation.

The following empirical methods have been used: observations, questioning and interviewing teachers for gathering primary pedagogical information; interviewing and surveying research and teaching staff, administrative staff and students of educational 
departments, workers of teachers' associations and federations in Great Britain, Canada and the USA for clearing out specifics of organizing collaboration with schools; attendance of lectures and discussions on pedagogical topics with participants of educational process; personal participation in workshops organized by Alberta Teachers' Association (Canada); implementation and examination of a manual and monographs.

\section{RESULTS}

In our research, teachers' professional development is regarded as a continuing process embracing three components. The permanent improvement of personal, social and professional competencies of a teacher, which coincides with the teacher career cycle is one of them.

With the aim of performing comparative analysis of teachers' professional development in the systems of continuing pedagogical education, on the basis of studying scientific-pedagogical literature and normative-legislative documentation of the researched countries, the use of the results of the empirical research done, there has been developed the Model of unification of teachers' professional development (Fig. 1) and the Model of diversification of teachers' professional development in the systems of continuing pedagogical education of Great Britain, Canada and the USA by the dominant trait (Fig. 2) that allowed to formulate their common and specific features.

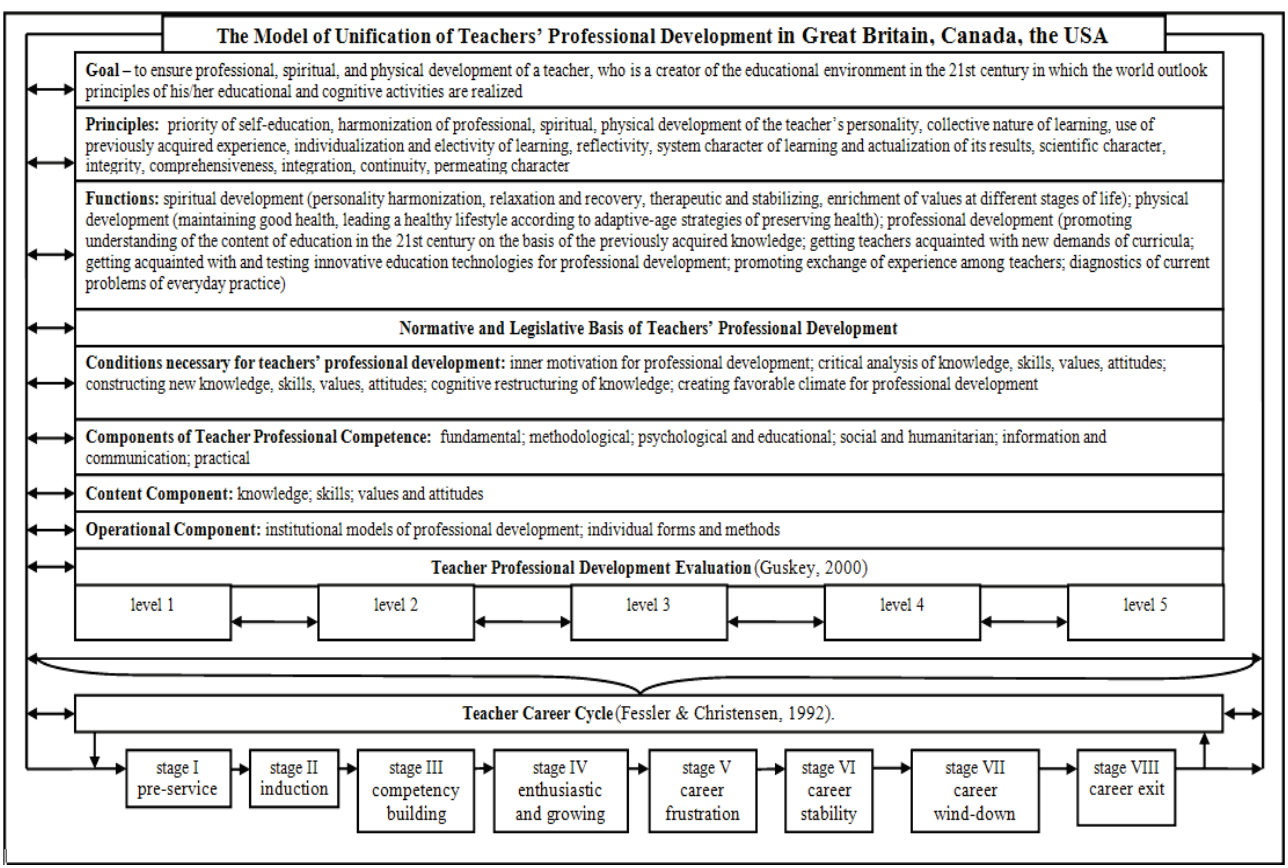

Fig. 1. The Model of Unification of Teachers' Professional Development in Great Britain, Canada, the USA

It has been discovered that in English-speaking countries the terms "continuing pedagogical education", "personnel professional development" and "professional learning" are often used as synonyms. 


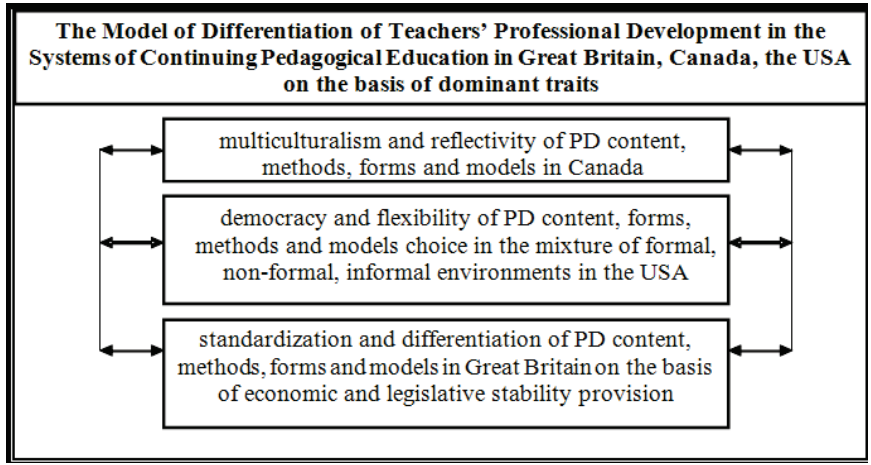

Fig. 2. The Model of Differentiation of Teachers' Professional Development in Great Britain, Canada, the USA on the Basis of Dominant Traits

Teachers' professional development is the process that begins at the stage of professional training at a higher education institution and is lifelong. While planning and organizing teachers' professional development, it is important to take account of the state of school education system development in the national and international environment: preservice, mechanical and operational stages.

It is possible to clarify the common features of public school teachers' CPD in three countries, which are presented in the Model of unification:

-the goal: to ensure the professional, spiritual and physical development of a teacher, who is a creator of the educational environment in the 21 st century in which the world outlook principles of his/her educational and cognitive activities are realized;

- principles: priority of self-education, harmonization of professional, spiritual, physical development of the teacher's personality, collective nature of learning, use of previously acquired experience, individualization and electivity of learning, reflectivity, system character of learning and actualization of its results, scientific character, integrity, comprehensiveness, integration, continuity, permeating character;

- functions: spiritual development (personality harmonization, relaxation and recovery, therapeutic and stabilizing, enrichment of values at different stages of life); physical development (maintaining good health, leading a healthy lifestyle according to adaptive-age strategies of preserving health); professional development (promoting understanding of the content of education in the 21 st century on the basis of the previously acquired knowledge; getting teachers acquainted with new demands of curricula; getting acquainted with and testing innovative education technologies for professional development; promoting exchange of experience among teachers; diagnostics of current problems of everyday practice);

- normative and legislative basis of teachers' CPD;

- conditions necessary for teachers' CPD: inner motivation for professional development; critical analysis of knowledge, skills, values, attitudes; constructing new knowledge, skills, values, attitudes; cognitive restructuring of knowledge; creating the favorable climate for professional development;

- components of teachers' CPD: fundamental; methodological; psychological and educational; social and humanitarian; information and communication; practical;

- content component: knowledge; skills; values and attitudes; 
- operational component: institutional models of professional development; individual forms and methods;

- evaluation of teachers' CPD, which has several levels;

- teacher's career cycle, which has several stages.

In the Model of diversification of teachers' professional development, we have presented the dominant traits of public school teachers' CPD in every country. It is multiculturalism and reflectivity of CPD content, methods, forms and models, which underpin the Canadian experience. We emphasize the democracy and flexibility of CPD content, forms, methods and models choice in the mixture of formal, non-formal, informal environments in the USA. And we accentuate the standardization and differentiation of CPD content, methods, forms and models in Great Britain on the basis of economic and legislative stability provision.

Professional development is necessary at all stages of teachers' career cycle: at the survival stage that is characterized by insufficient knowledge of teaching methods and by the desire to raise to the imaginary image of the excellent teacher; the adjustment stage: research and application of theoretical knowledge to everyday professional practice; the stage of accumulating experience: accumulation of knowledge in teaching methods, knowledge of academic programs, competencies and development of the own teaching style; the stage of maturity that is characterized by the awareness of belonging to the teaching profession, directing their activities to the comprehensive students development, showing professional enthusiasm; career wind-down and career exit.

The common principles on which teachers' professional development in the countries being studied is based have been revealed:

- objective reality and ideas of complex system projection of the educational process;

- social aspect of professional development and integrative relations between science, ideology, realities of society's everyday life as well as principles of autonomy and diversity;

- constructivism according to which knowledge is generated under the influence of internal (person's theories, ideas, interests, needs) and external (theories, experience, interests of other people) factors and effects;

- a complex of professional knowledge that is developing on the basis of various sources of origin: a) empirical - experience of working in educational environment and professional behavior; b) technological - educational technologies; c) personal - concepts and ideas of students, teachers, parents concerning different factors of the educational process; d) ethical and ideological - ideological, democratic concepts; e) interdisciplinary innovative evolutionary-realistic, constructivist, complex philosophic and epistemological concepts; f) knowledge of the school subject - concepts and methods of teaching academic disciplines related to the content of school education; g) social and political knowledge about the content of school education - social, political and cultural concepts; h) knowledge of pedagogical disciplines - concepts of pedagogical sciences and methods using interdisciplinary approach;

- content of practical knowledge based on research and professional development of teachers.

Evaluation of professional development programs is the instrument that is realized through five-level model (Guskey, 2000): level 1 - participants' reaction (the simplest way 
of gathering and analyzing information based on the participants' responses to the program); level 2 - participants' learning (evaluation of participants' knowledge and skills acquired during the program); level 3 - organization support and change (evaluation of the effect of the teachers' professional development program on the activities of the organization where they work and implementation of changes); level 4 - participants' use of new knowledge and skills (evaluation of the use of the acquired knowledge and skills in participants' teaching activities after the end of the program); level 5 - student learning outcomes (evaluation of the professional development program effect on teachers' activities and hence on their students' achievements). Evaluation allows to reveal positive and negative factors as well as to determine the effect of professional development on further teachers' activities, work of the public school and improvement of students' achievements.

The results of modern research are of significant importance for revealing positive and negative characteristics of the structural and functional organization of the system of continuing pedagogical education, professional development programs, professional development content, models, forms and methods. They facilitate the development of the theory of pedagogical science, on which teachers' professional development prognostics and development of the strategy for reforming education aimed at improving its quality as well as the practical realization of teachers' professional development in Great Britain, Canada and the USA are based.

\section{CONCLUSIONS}

The theoretical framework of teachers' professional development in Great Britain, Canada and the USA is grounded on complex integration of philosophic, psychological and pedagogical concepts and approaches; principles of self-education priority, harmonization of professional, spiritual, physical development of a teacher, collegiality of learning, application of the previous experience, individualization and electivity of learning, reflexivity, systemic character and actualization of the results of learning, scientific character, integrity, comprehensiveness, integration, continuity, permeating character; on the application of technological and academic, practical and phenomenological models of professional development.

Common for the countries studied is the availability of the phenomenon of teachers' professional development inter-culture that foresees interpenetration of the traditional and adopted culture being based on the mutual history of development, influence of international labor market of globalized character, on the state policies directed towards preserving national identity and allows to state that there is no "pure culture" of teachers" professional development in Great Britain, Canada and the USA.

Different are the following approaches that are applied in practice of teachers' professional development in the countries studied:

- conservatism and restraint in introducing educational innovations, strict adherence to educational traditions characteristic of Great Britain;

- significant role in the active social movement, development of initiative, intensive development of own undertakings and adoption of foreign experience promoting the wide implementation of educational innovations in the USA;

- application of the expecting-balanced approach to introducing innovations of the USA with the account of the conservatism of Great Britain, complex combination of American and British experience in Canada.

Prospects for future research include the analysis of content and operational components of public school teachers' CPD in the countries under research. 


\section{REFERENCES}

1. Andrew, M., Jelmberg, J. (2010). How Teachers Learn: An Educational Psychology of Teachers Preparation. ( $1^{\text {st }}$ ed). New York, NY : Peter Lang Publishing, 240 p.

2. Baker, S., Smith, S. (1999). Starting Off on the Right Foot: the Influence of Four Principles of Professional Development in Improving Literacy Instruction in Two Kindergarten Programs. Learning Disabilities Research and Practice, No 14 (4), pp. 239-253.

3. Beaty, L. (1998). The Professional Development of Teachers in Higher Education: Structures, Methods and Responsibilities. Innovations in Education and Training, No 35 (2), pp. 99-107.

4. Clarke, A. (1995). Professional Development in Practicum Settings: Reflective Practice under Scrutiny. Teacher and Teacher Education, Volume 11, No 3, pp. 243-261.

5. Cochran-Smith, M. (2003). Learning and Unlearning: the Education of Teacher Educators. Teaching and Teacher Education, No 19, pp. 5-28.

6. Fessler, R., Christensen, J. C. (1992). The Teacher Career Cycle: Understanding and Guiding the Professional Development of Teachers. Boston : Allyn and Bacon, 290 p.

7. Field, J., Latta, M. (2001). What Constitutes Becoming Experienced in Teaching and Learning? Teaching and Teacher Education, No 17, pp. 885-895.

8. Gay, G., Howard, T. (2000). Multicultural Teacher Education for the $21^{\text {st }}$ Century. The Teacher Education, Volume 36, Issue 1, pp. 1-16.

9. Guskey, T. (2000). Evaluating Professional Development. Thousand Oaks, CA : Corwin Press Inc., 328 p.

10. Joyce, B., Calhoun, E. (2010). Models of Professional Development: a Celebration of Educators. Thousand Oaks, CA : Corwin Press, $160 \mathrm{p}$.

11. Kauchak, D., Eggen, P. (2010). Introduction to Teaching: Becoming a Professional. (4 $4^{\text {th }}$ ed). Prentice Hall, 560 p.

12. Kelley, M. (2010). The Everything New Teacher Book: a Survival Guide for the First Year and beyond. ( $2^{\text {nd }}$ ed). Adams Media, 320 p.

13. Lieberman, A., Darling-Hammond, L. (2010). High Quality Teaching and Learning: International Perspective on Teacher Education (Teacher Quality and School Development $)$, (Eds), ( $1^{\text {st }}$ ed $)$. Routledge, $224 \mathrm{p}$.

14. Pratt, C., McGuigan, W., Katzev, A. (2000). Measuring Program Outcomes: Using Retrospective Pretest Methodology. American Journal of Evaluation, No 21 (3), pp. 341-349.

15. Reeves, D. (2010). Transforming Professional Development into Student Results. Alexandria, Virginia : Association for Supervision \& Curriculum Development, 156 p.

16. Scribner, J. (1999). Professional Development: Untangling the Influence of Work Context in Teacher Learning. Educational Administration Quarterly. Volume 35, No 2, pp. 238-266.

17. Villegas-Reimers, E. (2003). Teacher Professional Development: an International Review of the Literature. UNESCO : International Institute for Educational Planning, 197 p. 